\title{
The salivary glands as a privileged site of cytomegalovirus immune evasion and persistence
}

\author{
Ann E. Campbell • Victoria J. Cavanaugh • \\ Jacquelyn S. Slater
}

Received: 21 December 2007 / Published online: 8 February 2008

(C) Springer-Verlag 2008

\begin{abstract}
The salivary glands (SG) provide a haven for persistent cytomegalovirus replication, and in this regard are a privileged site of virus immune evasion. The murine cytomegalovirus (MCMV) model has provided insight into the immunological environment of the SG and the unqiue virus-host relationship of this organ. In response to MCMV infection, a robust $\mathrm{T}$ cell-mediated immune response is elicited, comprised predominantly of CD8+ T cells that phenotypically and functionally appear activated. However, they fail to clear virus by an unknown evasion mechanism that is independent of inhibitory NKG2A- or Programmed Death 1-mediated signaling. Virus is eventually eliminated from the SG by effector CD4+ T cells expressing antiviral cytokines. However, this mechanism is severely dampened by high levels of the immunosuppressive cytokine IL-10, selectively expressed by SG CD4+ T cells.
\end{abstract}

Keywords Murine cytomegalovirus · T cells $\cdot$ IL-10 . NKG2A · PD-1

\section{Introduction}

Herpesviruses use a variety of strategies to maintain their existence within the human population through transmission from acutely or latently-infected persons to noninfected individuals. Human cytomegalovirus (HCMV) is efficiently spread through contact with mucosal secretions containing infectious virus. These include saliva, semen,

A. E. Campbell $(\varangle) \cdot$ V. J. Cavanaugh · J. S. Slater Department of Microbiology and Molecular Cell Biology, Eastern Virginia Medical School, 700 W. Olney Road, Norfolk, VA 23507, USA

e-mail: campbeae@evms.edu vaginal and cervical secretions, and breast milk. There are two features of mucosal shedding of HCMV that are of particular epidemiological significance. One is the prolonged secretion of virus in saliva (as well as urine) for months following an acute, primary infection. This is best exemplified by reports that as high as $78 \%$ of toddlers attending day care centers in the United States shed HCMV in saliva for up to 2 years, and consequently, seronegative day care providers and mothers of infected children have annual infection rates ten times higher than expected [1-5].

A second feature is the intermittent and clinically unapparent excretion of reactivated virus in saliva, semen, cervical and vaginal secretions, and breast milk from latentlyinfected persons who have demonstrable immunity to HCMV. HCMV DNA was detected in $8.7 \%$ of semen samples from healthy infertility patients, the highest among all sexually transmitted viruses [7], and in approximately $3 \%$ of cryopreserved semen samples for sperm donations [8]. The percentage increases to as high as $65 \%$ in a subpopulation of HIV infected, antiretroviral therapy-naïve men [55]. HIV-infected persons, as well as transplant patients, also excrete HCMV in saliva at elevated frequencies (31 and $45 \%$, respectively) $[13,40]$. Particularly high is the frequency of HCMV isolated from or detected in breast milk of lactating, seropositive mothers. In fact, nearly all HCMV seropositive women will reactivate and shed virus during lactation [53]. Breast-milk acquired HCMV is clearly a source of transmission to the neonate who, if preterm, may experience at least transient disease [38, 43, 44, 61].

From the above, it is evident that the virus-host relationship at oral and genital mucosal sites is central to the pathogenesis and epidemiology of this clinically important virus. Also evident is the fact that the immune response to the virus at mucosal sites may be different from systemic immunity in that clearance is protracted and the incidence 
of reactivation is high. This review will focus on the immune response to cytomegalovirus in salivary glands (SG), with an emphasis on the mouse model using murine cytomegalovirus (MCMV). It is likely that at least some of the findings from studies of SG extend to other mucosal sites, particularly the mammary gland. Our laboratory attempted to extend this model to genital mucosa as well. However, repeated attempts to establish infection via the vaginal route in susceptible BALB/c mice were unsuccessful. This review will discuss the unique immunological features of the cellular response to virus in SG and potential reasons for immune evasion. Unless otherwise stated, the term "salivary glands" refers collectively to the parotid, sublingual, and submandibular glands. At least in BALB/c mice, each of these glands possess both effector and regulatory cells as components of salivary immunity [45].

\section{Immunological features of the cellular immune response to MCMV in salivary glands}

The murine model of CMV infection has demonstrated that SG are a unique site in regards to virus-cell interactions. Virus is seeded at this site as a consequence of secondary viremia, with blood monocytes playing a major role in MCMV dissemination [57]. This process may be assisted by the extraordinarily high rate of blood flow through SG tissue, due to an abundant capillary supply [30]. By 2 weeks post infection of the gland, intranuclear eosinophilic inclusion bodies, nuclear enlargement, and peripheral margination of chromatin are widely evident in glandular epithelial cells, accompanied by infiltrates of interstitial mononuclear cells [11]. In spite of the inflammatory response, this gland supports a chronic infection, with infectious virus replicating for months after virus is cleared from all other target organs. Persistent virus is selectively sequestered in vacuoles of glandular acinar epithelial cells [26]. Thus, a mysterious hallmark of SG infection is the immunological privilege bestowed upon the glandular epithelial cells that protects them from certain antiviral effector functions.

The eventual elimination of replicating virus from SG is independent of CD8+ T cells and is mediated, directly or indirectly, by CD4+ T cells [23]. Long term depletion of $\mathrm{CD} 4+\mathrm{T}$ cells from $\mathrm{BALB} / \mathrm{c}$ mice results in persistence of virus in the glandular epithelial cells of SG, where virus titers remain elevated $\left(10^{6} \mathrm{PFU} / \mathrm{gland}\right)$ for over 5 months. CD4+ T cell-independent, antiviral CD8+ T cells are generated in these mice, and are effective in eliminating virus from other target organs, such as spleen and lung, and from fibroblasts within the SG [26]. CD4+ T cells mediate their protective function through a combination of TNF $\alpha$ and IFN $\gamma$, as revealed through cytokine neutralization assays
$[32,46]$. These cytokines could have direct antiviral activity, and/or could assist in the activation or recruitment of other effector cells. Virus titers in the SG are enhanced significantly by treatment of the host with anti-NK1.1 [48] or anti-asialo GM1 antibodies [10]. Thus, it is possible that the $\mathrm{CD} 4+\mathrm{T}$ cells provide direct antiviral functions but also serve a regulatory function in mediating NK cell-like antiviral activities.

This potential scenario is similar to the situation where BALB/c and C57BL/6 mice depleted of CD8+ T cell function by administration of anti-CD8 antibody or by deletion of the beta- 2 microglobulin $\left(\beta_{2} \mathrm{~m}\right)$ gene, respectively, mount a surprisingly robust antiviral immune response that effectively eliminates MCMV from spleen, lung, and eventually SG, with kinetics similar to control or wild-type mice $[26,27]$. In these studies, effective viral clearance was mediated by $\mathrm{CD} 4+\mathrm{T}$ cells that were necessary but not sufficient. Thus, in certain circumstances, CD4+ T cells, in cooperation with another cell type, can exert antiviral functions equivalent to CD8+ CTL. Interestingly, the second, cooperating cell type may be different depending on the target organ. In the $\beta_{2} \mathrm{~m}$ knock-out (KO) mice, treatment with anti-NK1.1 antibody curtailed virus clearance in SG, but not spleen or lungs, where the cooperating effector cell remains undefined. More recently, a compensatory role of CD4+ T cells and NK cells has been described for immunity to melanoma, a tumor for which CD8+ CTL are necessary for immunity in immunocompetent mice. When mice are primed with melanoma antigen in the absence of CD8+ $\mathrm{T}$ cells, protection from tumor is effectively mediated by a synergy between an IFN-producing CD4+ T cells and cytolytic NK cells [49, 50]. In summary, MCMV-infected epithelial cells within the SG are uniquely "resistant" to CD8+ CTL, but virus within these cells is eventually eliminated by the synergistic action of CD4+ $\mathrm{T}$ cells and a second cooperating cell type with an NK-like phenotype. How these CD4+ T cells and NK-like cells compare, phenotypically and molecularly, to the compensatory cells generated in the absence of CD8+ T cells is a most intriguing question. As a final note, numerous studies have demonstrated that antibodies do not have a role in clearance of MCMV from any target organ, including the SG [23].

It appeared logical that $\mathrm{CD} 4+$ rather than $\mathrm{CD} 8+\mathrm{T}$ cells were protective in SG because the immunological environment of the mouse SG favors antibody production and a predominantly $\mathrm{Th} 2$ response. Indeed, the repertoire of lymphocytes in SG of uninfected mice is significantly different from peripheral or central lymphoid organs. The immunological environment of the submandibular salivary gland (SMG) mimics somewhat that of the gut in that IgA responses are favored; in fact, B cells in the SMG almost exclusively produce IgA [35-37]. Approximately half of the mononuclear cells are CD3+ $\mathrm{T}$ lymphocytes, equally 
divided between CD4+ and CD8+ T cells [36]. This ratio differs from that of the gut or even the draining periglandular and cervical lymph nodes, where CD4+ T lymphocytes predominate over CD8+ cells. There is a higher ratio of Th2 to Th1 CD4+ T cells in the SMG than in spleen or lymph nodes [36]. In the gland, cells producing IL-5 (a cytokine required for IgA production) exceed those producing IFN $\gamma$. Furthermore, a high percentage (6-10\%) of SMG $\mathrm{T}$ cells is negative for both CD4 and CD8 antigens (double negatives). All of these double negative cells express the gamma/delta $(\gamma / \delta)$ T cell receptor. In addition to the doublenegative cells, $25 \%$ of CD8+ T cells in the SMG express $\gamma /$ $\delta \mathrm{T}$ cell receptors, as opposed to the exclusively alpha/beta $(\alpha / \beta) \mathrm{T}$ cell receptors on CD4+ and CD8+ T cells in the draining lymph nodes [36]. The extent to which this characterization of resident SMG immune cells is influenced by mouse strain is unknown; nevertheless, it renders an appreciation for organ-specific differences in immunity that likely influence the response to pathogens.

Based on the above findings, the immune response to MCMV in the SMG was assessed by isolating, phenotyping, and characterizing the mononuclear cells that infiltrate the gland at various times post infection. When BALB/c mice are administered a high dose of virus, titers in the SMG reach $10^{7}-10^{8} \mathrm{PFU} / \mathrm{ml}$ from 14 to 21 days post infection, and by day 28 drop only $1 \log _{10}$. Virus also replicates in the lymph nodes draining the SG, the cervical and periglandular lymph nodes. However, virus titers at this site peak at day 14 post infection, then decline and become undetectable by day 28 post infection. Thus, comparisons can be made between the immune response in the lymph nodes, where virus is cleared, and the response in the adjacent SMG, where virus persists.

Using this model, we found that the BALB/c SMG mounts a surprisingly robust $\mathrm{CD} 8+\mathrm{T}$ cell response to MCMV infection [11] (Table 1). The CD8+ T cells are activated and produce IFN $\gamma$ ex vivo and in response to virus stimulation. There is a high frequency of virus (IE1)-specific $\mathrm{T}$ cells, as identified by tetramer staining, through at least 28 days post infection. These MHC class I-restricted CTL are cytolytic for MCMV-infected fibroblasts ex vivo. Other effector or regulatory cells that are increased in numbers in response to infection include (in order of abundance): NK T cells, CD4+ T cells, CD4+CD25+ T cells, TCR $\gamma / \delta$ T cells, and DC (including plasmacytoid DC). At least at the level of RNA, SMG mononuclear cells produced an abundance of IFN $\gamma$, IL-10, MIP1 $\beta$, and RANTES. In comparison, $\mathrm{CD} 4+\mathrm{T}$ cells dominated the draining lymph nodes, where the frequency of IE1 TCR + CD8+ T cells was lower (Table 1) and RANTES was the only chemokine or cytokine detectable at the level of RNA [11]. Therefore, MCMV replication persists in the SMG in the face of a robust response composed of activated CTL, NK T cells,
Table 1 Characteristics of the immune response to MCMV in the submandibular gland (SMG) compared to the draining lymph nodes (LN) 14 days post infection of BALB/c mice

\begin{tabular}{lcc}
\hline & SMG $(\%)$ & $\mathrm{LN}^{\mathrm{e}}(\%)$ \\
\hline $\mathrm{CD} 4+\mathrm{TCR} \alpha / \beta+$ & 18 & 60 \\
$\mathrm{CD} 8+\mathrm{TCR} \alpha / \beta+$ & 81 & 25 \\
$\mathrm{IE} 1 \mathrm{TCR}+{ }^{\mathrm{a}}$ & 9 & 2 \\
$\mathrm{NKG} 2 \mathrm{~A}+{ }^{\mathrm{b}}$ & 93 & 0 \\
$\mathrm{CD} 4+\mathrm{CD} 25+$ & 13 & 9 \\
$\mathrm{CD} 3+$ panNK+ & 23 & 1 \\
$\mathrm{CD} 3+\mathrm{TCR} \gamma \delta$ & 4 & 0.7 \\
$\mathrm{MCMV}$ IFN $\gamma+{ }^{\mathrm{c}}$ & 25 & 87 \\
$\mathrm{CD} 11 \mathrm{c}+\mathrm{I}-\mathrm{A}+$ & 15 & 0.6 \\
$\mathrm{CD} 11 \mathrm{~b}+\mathrm{CD} 8 \alpha+{ }^{\mathrm{d}}$ & 23 & 14 \\
\hline Data & &
\end{tabular}

Data are from Refs. [11, 12]

a Percentage of $\mathrm{CD} 8+\mathrm{TCR} \alpha / \beta+$-gated cells co-expressing CD8 and IE1 TCR

b Percentage of CD3+CD8+-gated cells co-expressing IE1 TCR and NKG2A

${ }^{\mathrm{c}}$ Percentage of total IFN $\gamma$-producing CD3+ cells that produced IFN $\gamma$ in response to MCMV-infected stimulator cells

${ }^{\mathrm{d}}$ Percentage of CD11c+I-A ${ }^{\mathrm{d}}+$-gated cells co-expressing $\mathrm{CD} 11 \mathrm{~b}$ and $\mathrm{CD} 8 \alpha$

e Draining lymph nodes include a pool of periglandular and cervical lymph nodes

and sources of potential antiviral cytokines. It should be noted that this response to MCMV is not restricted to the $\mathrm{BALB} / \mathrm{c}$ strain. Selective phenotypic analyses were performed on mononuclear cells isolated from the SMG of C57BL/6 mice (unpublished data). CD8 $+\mathrm{T}$ cells were dominant over CD4+ T cells at day 14 post infection (64\% compared to $32 \%$, respectively). Compared to the draining lymph nodes at this time point, there was a sevenfold increase in CD3 - NK cells, a fourfold increase in CD8 $+\gamma /$ $\delta \mathrm{TCR}+$ cells and a twofold increase in CD $3+\mathrm{NK}$ T cells. These results corroborate the many earlier studies documenting CD8+ $\mathrm{T}$ cell-independent control of MCMV in $\mathrm{SG}$, and demonstrate that this independence is not due to an inability of CTL to infiltrate SG or to become activated.

CD8+ CTL control of MCMV replication in SG cannot be totally dismissed, however. There may be individual target cells within this organ, such as fibroblasts, that are susceptible to CTL-mediated killing or to IFN $\gamma$-mediated antiviral functions of CTL. Indeed, virus infection of connective tissue fibroblasts within SG has been observed in severely immunodeficient mice, but not hosts with intact immunity [26]. In addition, mutant MCMV deleted of immune evasion genes that downregulate MHC class I (m06, m152) replicates to lower titers (approximately $1 \log _{10}$ ) in SG than WT virus due to $\mathrm{CD} 8+\mathrm{T}$ cell-mediated immune clearance [31]. This may reflect CTL control of virus in selective cell populations. 
Thus, the immunological privilege associated with persistent MCMV in SG may apply to a selective cell population, such as acinar epithelial cells.

\section{NKG2A and PD-1 receptors as potential inhibitors of CTL function in salivary glands}

One potential explanation for the inability of CD8+ CTL to clear virus from the SMG of a naïve host is that these effector cells receive inhibitory signals from surface receptors such as NKG2A or Programmed Death 1 (PD-1), both of which downregulate the antiviral responses of $\mathrm{CD} 8+\mathrm{T}$ cells during some persistent viral infections. For example, upregulation of CD94/NKG2A on polyoma virus-specific CTL results in downregulation of their antigen-specific cytotoxicity [42]. Neurons latently-infected with HSV are protected from cytotoxicity by CD94/NKG2A expressed on virus-specific memory CD8+ $\mathrm{T}$ cells [58]. However, expression of this receptor has no effect on the cytotoxic or cytokine producing functions of lymphocytic choriomeningitis virus (LCMV)-specific CTL [34, 39]. In addition to influencing cytolytic activity, CD94/NKG2A expression dramatically reduces apoptotic cell death in CD8+ T cells, thus permitting survival and contributing to clonal expansion and the size of memory pools in vivo [21]. At a minimum, expression of NKG2A on MCMV-specific T cells has been used as a sensitive marker for antigen-experienced $\mathrm{T}$ cells [20]. Collectively, the data indicate that CD94/ NKG2A expression could influence either CTL cytotoxicity or maintenance within the SMG, or merely reflect the activation state of these cells.

We therefore examined the extent to which CD94/ NKG2A expression on CD8+ T cells within the SMG influenced MCMV persistence. Rationale for these experiments was the fact that $93 \%$ of virus-specific SMG CTL express the receptor CD94/NKG2A and that the ligand for CD94/ NKG2A, a non-classical MHC class I molecule Qa- $1^{\text {b }}$, is upregulated by infection of SG tissue [12]. However, the presence of the receptor has no influence on the rate of virus clearance from the SMG [12]. This conclusion is based on studies using mice genetically devoid of surface CD94/NKG2A. The DBA/2 strain of mice from Jackson Laboratories, but not from several other commercial vendors, does not express the CD94 gene naturally and therefore lacks surface CD94/NKG2A receptors [59]. This phenotype is associated with a functional defect in the ability of NK cells to lyse Qdm/Qa-1 $1^{\mathrm{b}}$ expressing target cells in vivo [25]. Accordingly, DBA/2 mice from Jackson Laboratories (CD94-) and from Charles River Laboratories (CD94+) were infected with MCMV, and virus titers were quantitated in the SMG on days 4, 7, 14, 21, and 28 after infection. MCMV titers differed between the two strains only on day 7 following infection, where the titers of CD94- Jackson mice were approximately $1 \log _{10}$ less than that of the CD94+ Charles River mice. By day 14, virus titers in both strains were nearly identical, and remained similarly elevated through day 28 post infection. The difference in virus titers at day 7 post infection is likely due to variations in the genetic background of the two strains and not to the presence of CD94, as transgenic Jackson mice "reconstituted" with CD94 had similar virus titers on day 7 post infection as their CD94- littermates [12]. It is quite possible that at the cellular level, individual CTLs may receive an inhibitory signal through engagement of an NKG2A receptor with Qa- $1^{\mathrm{b}}$ expressed on an infected target cell. However, this mechanism clearly does not account for the failure of virus-specific CTLs as a population to clear persistent virus from SMG.

Engagement of the receptor PD-1 on T cells with its ligands PD-L1 or PD-L2 can also dampen T cell-mediated immune responses to antigen. This receptor-ligand interaction functions to prevent autoimmunity and perhaps immune-mediated tissue damage during infections [28, 54]. However, during chronic viral infections, such as LCMV, human immunodeficiency virus, and hepatitis $\mathrm{C}$ virus, $\mathrm{PD}$ 1/PD-L1 interactions lead to $T$ cell exhaustion, such that virus-specific $\mathrm{CD} 8+\mathrm{T}$ cells are incapable of clearing virus $[6,19]$. There is in fact a positive correlation between the density of PD-1 expression on $\mathrm{T}$ cells and antigen load, with low PD-1 expression on T cells and low antigen load during acute infection when fully functional $\mathrm{T}$ cells are present, to high PD-1 expression on T cells within the environment of high antigen load during a persistent infection. Gradations in the density of PD-1 expression, antigen load, and degree of exhaustion exist between these two extremes. For example, partial exhaustion of $\mathrm{T}$ cells is exhibited by the absence of IL-2 production and CTL lytic function, with declining IFN $\gamma$ and TNF $\alpha$ production. Full exhaustion is characterized by the absence of each of these cytokines, no CTL lysis, lack of proliferation, and a high degree of T cell apoptosis [19]. Because PD-1 is upregulated by antigen-activation of $\mathrm{T}$ cells, this receptor is also considered a marker of $\mathrm{T}$ cell activation. During persistent viral infections, therefore, one must distinguish between PD-1 as an indicator of $\mathrm{T}$ cell exhaustion that contributes to virus persistence, or PD-1 as an activation marker that is sustained due to persistent viral antigen and therefore $\mathrm{T}$ cell activation. This important distinction can be made by quantitating the amount of IL-2, TNF $\alpha$, and IFN $\gamma$ produced by virusspecific $\mathrm{T}$ cells, their proliferative potential, and their cytolytic function. Furthermore, restoration of the above $\mathrm{T}$ cell functions and effective viral clearance upon administration of blocking antibodies to PD-1 or PD-L1 is definitive proof of the negative regulatory function of this receptor-ligand interaction $[6,19]$. 
In order to determine if PD-1/PD-L1 interaction contributes to persistent MCMV infection of the SMG, we first assessed the expression of PD-1 on MCMV-specific CD8+ $\mathrm{T}$ cells within the SMG at day 21 post infection, a peak time of virus persistence in this gland. The results indicated that $73 \%$ of IE1-tetramer positive cells expressed surface PD-1 (Fig. 1). Expression of this molecule could simply be an indication of $\mathrm{T}$ cell activation, as $97 \%$ of tetramer+ cells were CD44+ (Fig. 1). Alternatively, PD-1 expression could signify that $\mathrm{T}$ cells were experiencing exhaustion. If this were the case, these cells were not fully exhausted. The percentage of IE1 tetramer+ CD8+ T cells increased from day 21 to day 28 post infection [11], a finding incompatible with either anti-proliferation or apoptosis. SG-derived CD8+ CTL were cytolytic, at least ex vivo, and MCMV-specific T cells produced IFN $\gamma$ at 21 days post infection. However, compared to cells in the draining lymph nodes, the percentage of cells producing IFN $\gamma$ in response to viral antigens in the SMG was significantly lower. In the cervical and periglandular lymph nodes, from which virus is cleared, $87 \%$ of cells capable of producing IFN $\gamma$ did so in response to stimulation with MCMV-infected cells (Table 1) [11]. In the
SMG, only $25 \%$ of all cells capable of producing IFN $\gamma$ did so upon virus stimulation. This may be indicative of declining IFN $\gamma$ production, perhaps signifying at least partial exhaustion mediated by PD-1/PD-L1 interaction.

In order to functionally test the significance of the above findings, we blocked PD-1/PD-L1 interactions in vivo by administration of anti-PD-L1 antibody, according to previously published procedures [6]. Compared to administration of isotype-matched control antibody, there was no significant difference in the rate of viral clearance, with nearly identical virus titers on days 14, 21, 28, and 35 post infection (Fig. 2). We therefore conclude that expression of PD-1 on MCMV-specific CTL reflected T cell activation, and that PD-1/PD-L1 interactions did not contribute significantly to $\mathrm{T}$ cell exhaustion and virus persistence in this organ.

\section{IL-10 as a potential inhibitor of antiviral activity in salivary glands}

One striking observation reported by Cavanaugh et al. [11] is the high level of expression of IL-10 RNA from

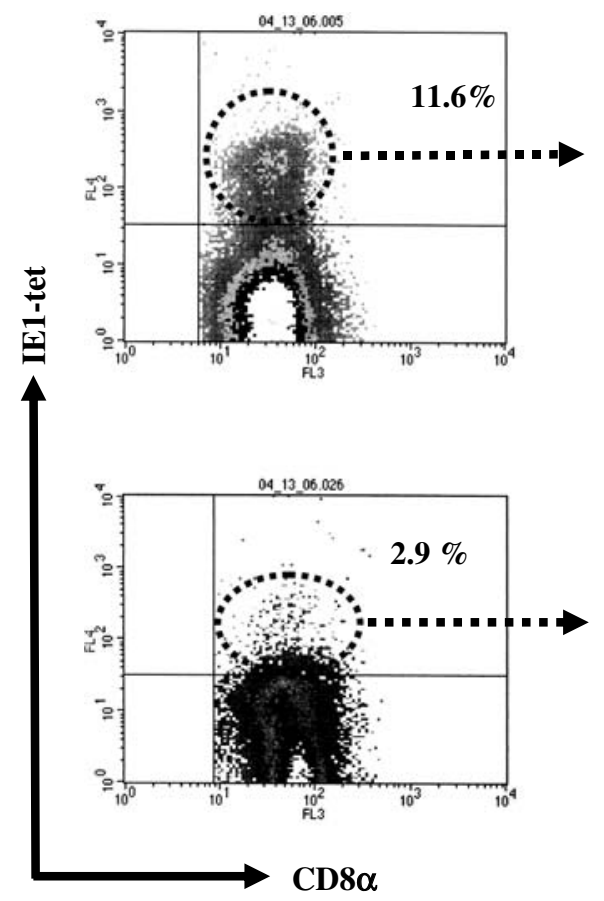

Fig. 1 PD-1 and CD44 expression on MCMV-specific CD8+ T lymphocytes. Male BALB/c mice ( 6 weeks of age) were infected intraperitoneally with $4 \times 10^{3} \mathrm{PFU}$ of virulent, salivary gland-passaged MCMV, and their submaxillary salivary glands (SMG) and draining lymph nodes (LN) were harvested on day 21 post infection. Leukocytes were isolated from these tissues and MCMV-specific CD8+ T lymphocytes were identified by flow cytometry using a tetrameric complex of mouse $\mathrm{H}-2 \mathrm{~L}^{\mathrm{d}}$ and a nonapeptide from MCMV pp89 as previously described [12]. Peptide-specific CD8+ T cells (circled in top and bottom left panels) were further analyzed for surface expression of
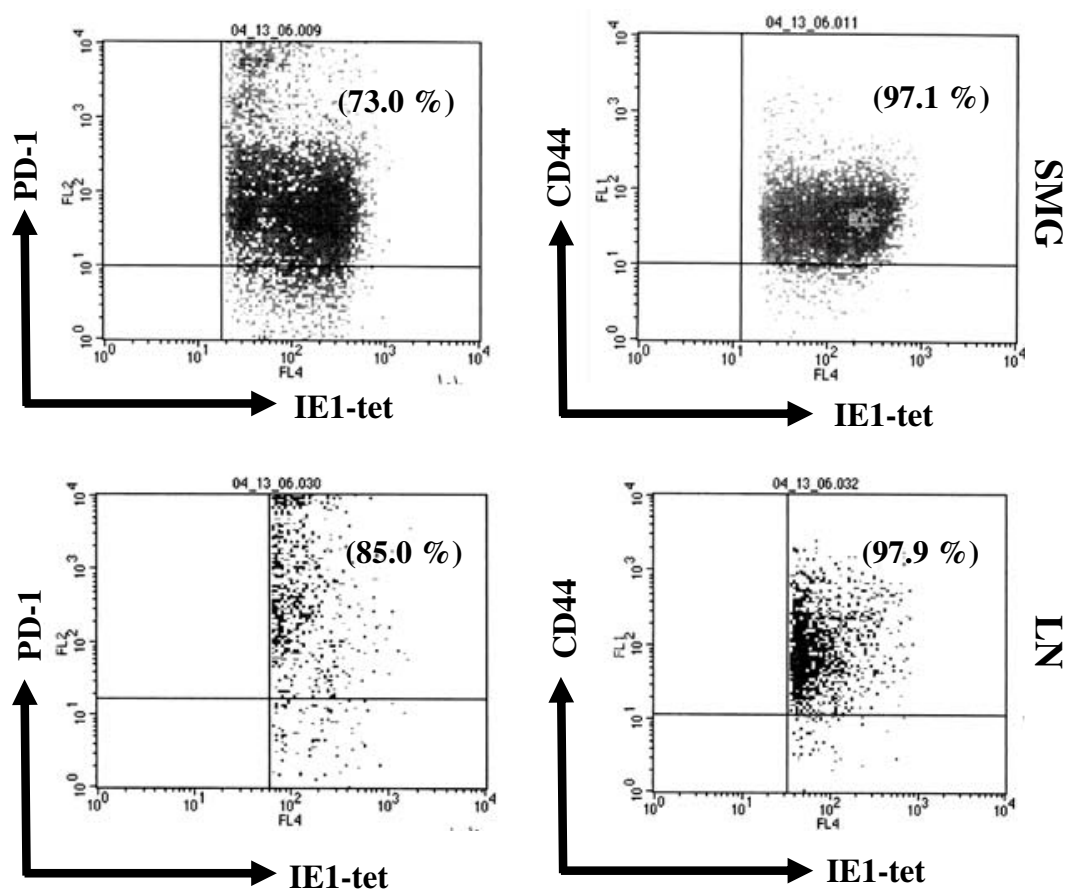

PD-1 (clone J43, BD Biosciences) and CD44 (clone IM7, BD Biosciences). The data represented in the left dot plots is that of gated CD3+ T cells expressing $\mathrm{CD} 8 \alpha$ and the tetramer, and the percentages indicate the proportion of CD8+ T cells that are peptide-specific. The data represented in the middle (top and bottom) and right (top and bottom) dot plots is that of gated tetramer-positive CD8+ T cells expressing PD-1 and CD44, respectively. Percentages in parentheses are adjusted numbers corrected for nonspecific staining of isotype-matched control antibodies (data not shown) 


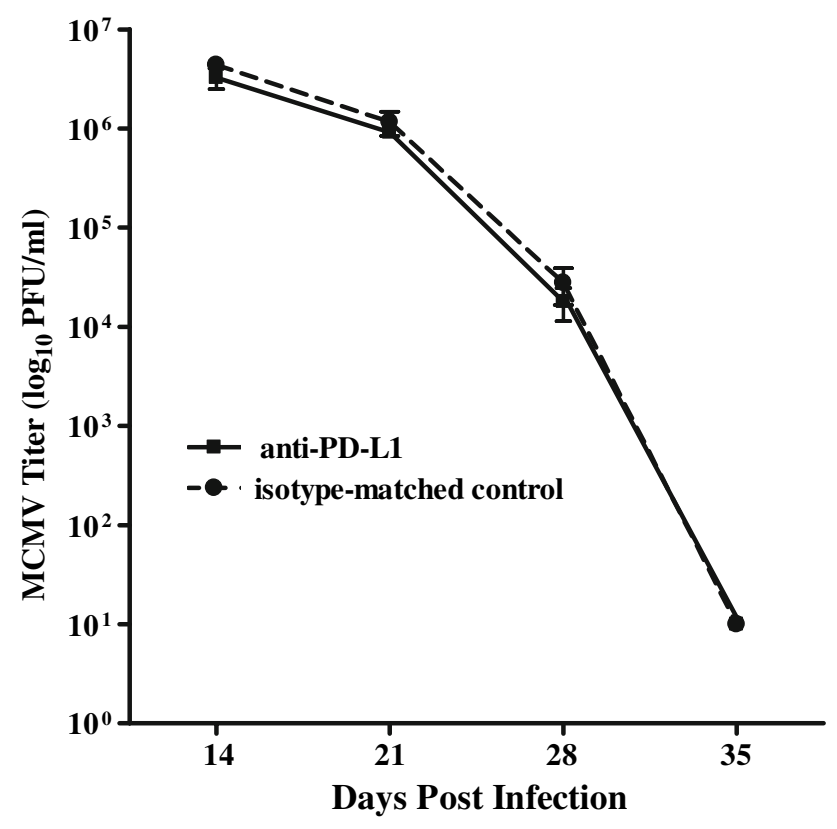

Fig. 2 MCMV titers in SMG of infected mice treated with anti-PD-L1 blocking antibody. Adult male BALB/c mice ( 6 weeks of age) were infected intraperitoneally with $4 \times 10^{2}$ PFU of virulent, salivary glandpassaged MCMV. Beginning on day 7 following infection, $200 \mu \mathrm{g}$ of rat anti-mouse PD-L1 (clone 10F.9G2), or rat IgG2b isotype control (Bio Express, West Lebanon, NH, USA) were administered intraperitoneally every third day through day 35 post infection as previously described [6]. Groups of four to six mice in each treatment group were sacrificed on days 14, 21, 28, and 35 after MCMV infection, and their SMG were harvested. Viral titers in the SMG were determined by standard plaque assays. The results are presented as the $\log _{10}$ of infectious MCMV per milliliter of tissue homogenate with standard error bars. The limit of detection was $10^{1} \mathrm{PFU} / \mathrm{ml}$

mononuclear cells isolated from the SMG of MCMVinfected BALB/c mice. Selective expression of IL-10 in this tissue was evident as early as day 6 post infection, with significant elevation by day 14 post infection. In contrast, IL-10 RNA was undetectable by RNase protection in the spleen and draining lymph nodes at either time post infection, suggesting tissue-selective expression of this cytokine in response to MCMV. The extent to which the cytokine RNA levels correlate with protein expression was not determined in these experiments, as the quantity of IL-10 produced by individual mononuclear cells, in the absence of in vitro stimulation, was below the level of detection by intracellular cytokine staining.

It is logical to speculate that IL-10 may exert suppressive effects on the clearance of MCMV selectively from the SG because IL-10 preferentially inhibits CD4+ T cell, as well as monocyte/macrophage, functions [41]. Studies have clearly shown that antiviral functions mediated by CD8+ $\mathrm{T}$ cells that are CD4+ $\mathrm{T}$ cell-dependent, such as those controlling persistent LCMV infection [33], are adversely affected by IL-10 $[9,18]$. However, IL-10 enhances the proliferation, differentiation, and cytokine activity of CD8+ $\mathrm{T}$ cells and NK cells [41]. Because anti-MCMV CTL induction and maintenance is independent of CD4+ T cells [26], IL-10 expression may not explain why MCMV-specific CTLs fail to clear virus from the glands, but may influence the overall antiviral potency of the effector CD4+ T cells.

Indeed, a recent study has shown that IL-10 induced in response to MCMV infection of the SG of C57BL/6 mice suppresses clearance of the virus from this mucosal site [24]. IL-10 is produced selectively within SG and predominately by $\mathrm{CD} 4+\mathrm{T}$ cells lacking the phenotype of conventional Th2 or naturally occurring $\mathrm{T}$ regulatory cells. Importantly, in vivo blockade of IL-10 signaling using antagonist anti-IL-10 receptor antibodies enhances IFN $\gamma$ production by $\mathrm{CD} 4+\mathrm{T}$ cells and promotes clearance of infectious virus from the glands, even when the antibodies are administered subsequent to virus infection. The investigators hypothesize that IL-10 likely functions by suppressing expression of co-stimulatory ligands and/or antiviral cytokines by antigen-presenting cells. Thus, IFN $\gamma$ produced specifically by CD4+ $\mathrm{T}$ cells and negatively regulated by IL-10 may be a critical determinant in controlling MCMV replication in SG. The extent to which IL-10 directly or indirectly regulates CTL function in this gland remains unknown.

We used another approach to assessing the function of IL-10 in MCMV clearance from CD4+ T cell-dependent and -independent organs by assessing virus titers in BALB/ c IL-10 KO mice. Surprisingly, the KO mice were more susceptible to MCMV infection than wild-type control mice, such that by day 7 post infection, all IL-10 KO mice had either succumbed to infection or were moribund and therefore sacrificed. Virus titers in the SMG were lower in the IL-10 KO mice even at this early time post infection (Fig. 3). These data are in agreement with the above published study indicating that virus is cleared more efficiently in the absence of IL-10. However, this model using KO mice must consider the fact that these animals may be compromised in the ability of monocytes to traffic to SG, the primary means by which virus seeds this organ. Indeed, IL10 modulates expression of chemokine receptors on at least human monocytes, with reports of IL-10 mediated upregulation of CCR2, CCR5, and CXCR4 [14, 16, 47, 56, 60]. It is possible therefore that in the absence of IL-10, less virus entered the SG, as opposed or in addition to more rapid and efficient viral clearance.

In contrast, MCMV titers in the livers of the KO mice were nearly $3 \log _{10}$ higher compared to wild-type animals (Fig. 3), and this likely contributed to their rapid death. In this organ, virus replication is controlled by NK cells as well as CD8+ T cells [15, 17, 22, 29, 51, 52]. These data are consistent with reports that IL-10 enhances the growth and 


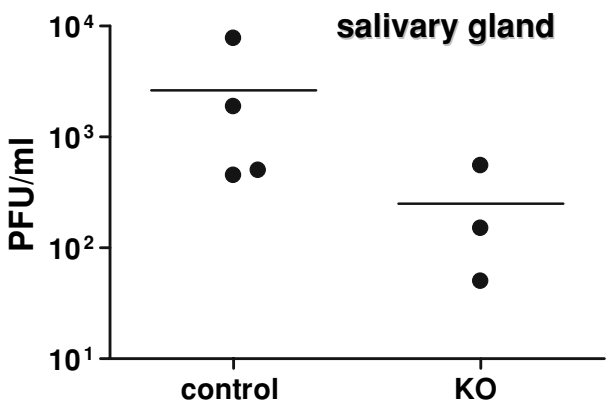

Fig. 3 MCMV replication in IL-10 knock-out (KO) mice. BALB/c IL-10 KO mice (C.129-IL-10 ${ }^{\mathrm{tm} 1 \mathrm{Cgn}}$, Jackson Laboratories, Bar Harbor, ME, USA) or wild-type BALB/c (controls) were infected intraperitoneally with $4 \times 10^{3} \mathrm{PFU}$ salivary-gland passaged MCMV. At 7 days

function of these effector cells [41]; thus, the lack of IL-10 may have compromised antiviral activities in this organ. These data suggest that IL-10 may have differential effects within specific organs depending on the CD4+ $\mathrm{T}$ cell dependence of antiviral activities. The MCMV model of infection appears to be unique in the fact that the SG are a $\mathrm{CD} 4+\mathrm{T}$ cell-dependent organ, hence negatively regulated by IL-10, while the other major target organs are more NK and/or CD8+ T cell dependent with respect to viral clearance and therefore positively (or at least not negatively) influenced by IL-10. In support of this, virus titers in other target organs such as lung and intestines were nearly identical between wild-type and IL-10 KO mice (data not shown).

\section{Summary}

It is evident from the above data and review of the literature that at least two different evasion strategies are operative within SG of MCMV-infected mice. First, a robust CD8+ CTL response is elicited at this mucosal site; however, infected epithelial cells are apparently refractory to CTLmediated antiviral effector functions. This brings us back to a suggestion made many years ago that acinar epithelial cells of the SG may be inherently resistant to CTL effector functions, perhaps due to aberrant antigen processing and/ or presentation in these target cells [24]. Eighteen years later, this hypothesis still requires testing. Immortalized mouse SG epithelial cell lines [12] that are highly permissive for MCMV replication process and present, to some extent, MCMV peptides to CTL (unpublished data). However, these cells may not be reflective of those within the microenvironment of the SG.

A second evasion strategy is mediated by IL-10 producing CD4+ T cells within the glands [24]. Although some asyet-undefined subpopulation of CD4+ T cells eventually mediates antiviral functions at this mucosal site, IL-10

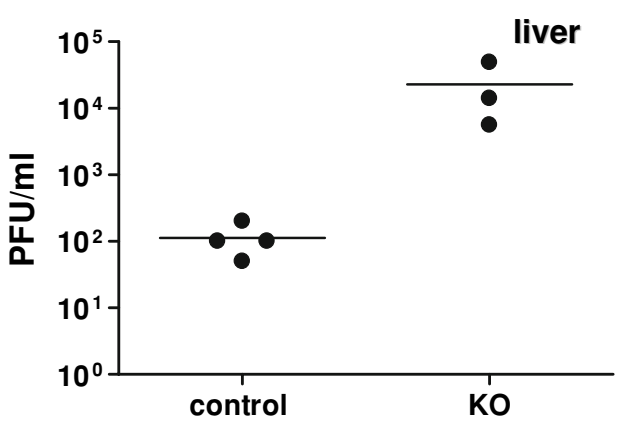

post infection, animals were sacrificed and organs harvested for virus titration by plaque assay. Dots represent individual mice; horizontal lines indicate mean titers

exerts immunosuppressive activity that results in delayed viral clearance. The two evasion strategies may function independently or perhaps in a causal relationship to provide efficient transmission of the virus while sparing the well being of the host.

Acknowledgments We gratefully acknowledge the generous contribution of Dr Gordon J. Freeman (Department of Medical Oncology, Dana-Farber Cancer Institute, Department of Medicine, Harvard Medical School, Boston, MA) who provided the anti-PD-L1 blocking antibodies. This work was supported by U.S. Department of Health and Human Services grant R03 AI45084 (AEC) and partially by grant R01 CA41451 (AEC).

\section{References}

1. Adler SP (1989) Cytomegalovirus and child day care. Evidence for an increased infection rate among day-care workers. N Engl J Med 321:1290-1296

2. Adler SP (1991) Cytomegalovirus and child day care: risk factors for maternal infection. Pediatr Infect Dis J 10:590-594

3. Adler SP (1991) Molecular epidemiology of cytomegalovirus: a study of factors affecting transmission among children at three day-care centers. Pediatr Infect Dis J 10:584-590

4. Adler SP (1992) Cytomegalovirus transmission and child day care. Adv Pediatr Infect Dis 7:109-122

5. Adler SP, Marshall B (2007) Cytomegalovirus infections. Pediatr Rev 28:92-100

6. Barber DL, Wherry EJ, Masopust D, Zhu B, Allison JP, Sharpe AH, Freeman GJ, Ahmed R (2006) Restoring function in exhausted CD8 T cells during chronic viral infection. Nature 439:682-687

7. Bezold G, Politch JA, Kiviat NB, Kuypers JM, Wolff H, Anderson DJ (2007) Prevalence of sexually transmissible pathogens in semen from asymptomatic male infertility patients with and without leukocytospermia. Fertil Steril 87:1087-1097

8. Bresson JL, Clavequin MC, Mazeron MC, Mengelle C, Scieux C, Segondy M, Houhou N (2003) Risk of cytomegalovirus transmission by cryopreserved semen: a study of 635 semen samples from 231 donors. Hum Reprod 18:1881-1886

9. Brooks DG, Trifilo MJ, Edelmann KH, Teyton L, McGavern DB, Oldstone MB (2006) Interleukin-10 determines viral clearance or persistence in vivo. Nat Med 12:1301-1309

10. Bukowski JF, Welsh RM (1985) Inability of interferon to protect virus-infected cells against lysis by natural killer (NK) cells 
correlates with NK cell-mediated antiviral effects in vivo. J Immunol 135:3537-3541

11. Cavanaugh VJ, Deng Y, Birkenbach MP, Slater JS, Campbell AE (2003) Vigorous innate and virus-specific cytotoxic T-lymphocyte responses to murine cytomegalovirus in the submaxillary salivary gland. J Virol 77:1703-1717

12. Cavanaugh VJ, Raulet DH, Campbell AE (2006) Up-regulation of CD94/NKG2A receptors and Qa-1b ligand during murine cytomegaloviirus infection of the salivary gland. J Gen Virol 88:1440 1445

13. Correia-Silva Jde F, Victoria JM, Guimaraes AL, Salomao UE, de Abreu MH, Bittencourt H, Gomez RS (2007) Cytomegalovirus shedding in the oral cavity of allogeneic haematopoietic stem cell transplant patients. Oral Dis 13:163-169

14. D’Amico G, Frascaroli G, Bianchi G, Transidico P, Doni A, Vecchi A, Sozzani S, Allavena P, Mantovani A (2000) Uncoupling of inflammatory chemokine receptors by IL-10: generation of functional decoys. Nat Immunol 1:387-391

15. Daniels KA, Devora G, Lai WC, O’Donnell CL, Bennett M, Welsh RM (2001) Murine cytomegalovirus is regulated by a discrete subset of natural killer cells reactive with monoclonal antibody to ly49h. J Exp Med 194:29-44

16. Debes GF, Dahl ME, Mahiny AJ, Bonhagen K, Campbell DJ, Siegmund K, Erb KJ, Lewis DB, Kamradt T, Hamann A (2006) Chemotactic responses of IL-4-, IL-10-, and IFN-gamma-producing CD4+ T cells depend on tissue origin and microbial stimulus. J Immunol 176:557-566

17. Dokun AO, Chu DT, Yang L, Bendelac AS, Yokoyama WM (2001) Analysis of in situ NK cell responses during viral infection. J Immunol 167:5286-5293

18. Ejrnaes M, Filippi CM, Martinic MM, Ling EM, Togher LM, Crotty S, von Herrath MG (2006) Resolution of a chronic viral infection after interleukin-10 receptor blockade. J Exp Med 203:2461-2472

19. Freeman GJ, Wherry EJ, Ahmed R, Sharpe AH (2006) Reinvigorating exhausted HIV-specific T cells via PD-1-PD-1 ligand blockade. J Exp Med 203:2223-2227

20. Gold MC, Munks MW, Wagner M, McMahon CW, Kelly A, Kavanagh DG, Slifka MK, Koszinowski UH, Raulet DH, Hill AB (2004) Murine cytomegalovirus interference with antigen presentation has little effect on the size or the effector memory phenotype of the CD8 T cell response. J Immunol 172:6944-6953

21. Gunturi A, Berg RE, Forman J (2004) The role of CD94/NKG2 in innate and adaptive immunity. Immunol Res 30:29-34

22. Hokeness KL, Deweerd ES, Munks MW, Lewis CA, Gladue RP, Salazar-Mather TP (2007) CXCR3-dependent recruitment of antigen-specific $\mathrm{T}$ lymphocytes to the liver during murine cytomegalovirus infection. J Virol 81:1241-1250

23. Holtappels R, Munks MW, Podlech J, Reddehase MJ (2006) CD8 T-cell-based immunotherapy of cytomegalovirus disease in the mouse model of the immunocompromised bone marrow transplant recipient, p. 383418. In: Reddehase MJ (ed) Cytomegaloviruses: molecular biology and immunology. Caister Academic, Norfolk

24. Humphreys IR, de Trez C, Kinkade A, Benedict CA, Croft M, Ware CF (2007) Cytomegalovirus exploits IL-10-mediated immune regulation in the salivary glands. J Exp Med 204:1217-1225

25. Jia SH, Kurepa Z, Bai A, Forman J (2000) Comparative ability of Qdm/Qa-1b, kb, and Db to protect class Ilow cells from NK-mediated lysis in vivo. J Immunol 165:6142-6147

26. Jonjic S, Mutter W, Weiland F, Reddehase MJ, Koszinowski UH (1989) Site-restricted persistent cytomegalovirus infection after selective long-term depletion of CD4+ T lymphocytes. J Exp Med 169:1199-1212

27. Jonjic S, Pavic I, Lucin P, Rukavina D, Koszinowski UH (1990) Efficacious control of cytomegalovirus infection after long-term depletion of CD8+ T lymphocytes. J Virol 64:5457-5464
28. Keir ME, Francisco LM, Sharpe AH (2007) PD-1 and its ligands in T-cell immunity. Curr Opin Immunol 19:309-314

29. Loh J, Chu DT, O'Guin AK, Yokoyama WM, Virgin HWt (2005) Natural killer cells utilize both perforin and gamma interferon to regulate murine cytomegalovirus infection in the spleen and liver. J Virol 79:661-667

30. Lu FX, Jacobson RS (2007) Oral mucosal immunity and HIV/SIV infection. J Dent Res 86:216-226

31. Lu X, Pinto AK, Kelly AM, Cho KS, Hill AB (2006) Murine cytomegalovirus interference with antigen presentation contributes to the inability of $\mathrm{CD} 8 \mathrm{~T}$ cells to control virus in the salivary gland. $\mathrm{J}$ Virol 80:4200-4202

32. Lucin P, Jonjic S, Messerle M, Polic B, Hengel H, Koszinowski UH (1994) Late phase inhibition of murine cytomegalovirus replication by synergistic action of interferon-gamma and tumour necrosis factor. J Gen Virol 75(Pt 1):101-110

33. Matloubian M, Concepcion RJ, Ahmed R (1994) CD4+ T cells are required to sustain $\mathrm{CD} 8+$ cytotoxic T-cell responses during chronic viral infection. J Virol 68:8056-8063

34. McMahon CW, Zajac AJ, Jamieson AM, Corral L, Hammer GE, Ahmed R, Raulet DH (2002) Viral and bacterial infections induce expression of multiple NK cell receptors in responding CD8(+) T cells. J Immunol 169:1444-1452

35. Mega J, Fujihashi K, Yamamoto M, McGhee JR, Hirasawa M, Kiyono H (1992) Cytokine production and T cell receptor expression by salivary gland $\mathrm{T}$ cells and intraepithelial $\mathrm{T}$ lymphocytes for the regulation of the IgA response. Adv Exp Med Biol 327:119131

36. Mega J, McGhee JR, Kiyono H (1992) Cytokine- and Ig-producing T cells in mucosal effector tissues: analysis of IL-5- and IFNgamma-producing $\mathrm{T}$ cells, $\mathrm{T}$ cell receptor expression, and $\operatorname{IgA}$ plasma cells from mouse salivary gland-associated tissues. J Immunol 148:2030-2039

37. Mega J, McGhee JR, Kiyono H (1995) Characterization of cytokine producing T cells, TCR expression, and IgA plasma cells in salivary gland-associated tissues. Adv Exp Med Biol 371B:1103-1108

38. Meier J, Lienicke U, Tschirch E, Kruger DH, Wauer RR, Prosch S (2005) Human cytomegalovirus reactivation during lactation and mother-to-child transmission in preterm infants. J Clin Microbiol 43:1318-1324

39. Miller JD, Peters M, Oran AE, Beresford GW, Harrington L, Boss JM, Altman JD (2002) CD94/NKG2 expression does not inhibit cytotoxic function of lymphocytic choriomeningitis virus-specific CD8+ T cells. J Immunol 169:693-701

40. Miller CS, Berger JR, Mootoor Y, Avdiushko SA, Zhu H, Kryscio RJ (2006) High prevalence of multiple human herpesviruses in saliva from human immunodeficiency virus-infected persons in the era of highly active antiretroviral therapy. J Clin Microbiol 44:2409-2415

41. Moore KW, de Waal Malefyt R, Coffman RL, O'Garra A (2001) Interleukin-10 and the interleukin-10 receptor. Annu Rev Immunol 19:683-765

42. Moser JM, Gibbs J, Jensen PE, Lukacher AE (2002) CD94NKG2A receptors regulate antiviral CD8(+) T cell responses. Nat Immunol 3:189-195

43. Neuberger P, Hamprecht K, Vochem M, Maschmann J, Speer CP, Jahn G, Poets CF, Goelz R (2006) Case-control study of symptoms and neonatal outcome of human milk-transmitted cytomegalovirus infection in premature infants. J Pediatr 148:326-331

44. Omarsdottir S, Casper C, Zweygberg Wirgart B, Grillner L, Vanpee M (2007) Transmission of cytomegalovirus to extremely preterm infants through breast milk. Acta Paediatr 96:492-494

45. Oudghiri M, Seguin J, Deslauriers N (1986) The cellular basis of salivary immunity in the mouse: incidence and distribution of $\mathrm{B}$ cells, T cells and macrophages in single-cell suspensions of the major salivary glands. Eur J Immunol 16:281-285 
46. Pavic I, Polic B, Crnkovic I, Lucin P, Jonjic S, Koszinowski UH (1993) Participation of endogenous tumour necrosis factor alpha in host resistance to cytomegalovirus infection. J Gen Virol 74(Pt 10):2215-2223

47. Pettersson A, Sabirsh A, Bristulf J, Kidd-Ljunggren K, Ljungberg B, Owman C, Karlsson U (2005) Pro- and anti-inflammatory substances modulate expression of the leukotriene B4 receptor, BLT1, in human monocytes. J Leukoc Biol 77:1018-1025

48. Polic B, Jonjic S, Pavic I, Crnkovic I, Zorica I, Hengel H, Lucin P, Koszinowski UH (1996) Lack of MHC class I complex expression has no effect on spread and control of cytomegalovirus infection in vivo. J Gen Virol 77:217-225

49. Prins RM, Vo DD, Khan-Farooqi H, Yang MY, Soto H, Economou JS, Liau LM, Ribas A (2006) NK and CD4 cells collaborate to protect against melanoma tumor formation in the brain. J Immunol 177:8448-8455

50. Ribas A, Wargo JA, Comin-Anduix B, Sanetti S, Schumacher LY, McLean C, Dissette VB, Glaspy JA, McBride WH, Butterfield LH, Economou JS (2004) Enhanced tumor responses to dendritic cells in the absence of CD8-positive cells. J Immunol 172:47624769

51. Salazar-Mather TP, Hokeness KL (2006) Cytokine and chemokine networks: pathways to antiviral defense. Curr Top Microbiol Immunol 303:29-46

52. Salazar-Mather TP, Orange JS, Biron CA (1998) Early murine cytomegalovirus (MCMV) infection induces liver natural killer (NK) cell inflammation and protection through macrophage inflammatory protein 1alpha (MIP-1alpha)-dependent pathways. J Exp Med 187:1-14

53. Schleiss MR (2006) Role of breast milk in acquisition of cytomegalovirus infection: recent advances. Curr Opin Pediatr 18:48-52

54. Sharpe AH, Wherry EJ, Ahmed R, Freeman GJ (2007) The function of programmed cell death 1 and its ligands in regulating autoimmunity and infection. Nat Immunol 8:239-245
55. Sheth PM, Danesh A, Sheung A, Rebbapragada A, Shahabi K, Kovacs C, Halpenny R, Tilley D, Mazzulli T, MacDonald K, Kelvin D, Kaul R (2006) Disproportionately high semen shedding of HIV is associated with compartmentalized cytomegalovirus reactivation. J Infect Dis 193:45-48

56. Sozzani S, Ghezzi S, Iannolo G, Luini W, Borsatti A, Polentarutti N, Sica A, Locati M, Mackay C, Wells TN, Biswas P, Vicenzi E, Poli G, Mantovani A (1998) Interleukin 10 increases CCR5 expression and HIV infection in human monocytes. J Exp Med 187:439-444

57. Stoddart CA, Cardin RD, Boname JM, Manning WC, Abenes GB, Mocarski ES (1994) Peripheral blood mononuclear phagocytes mediate dissemination of murine cytomegalovirus. J Virol 68:6243-6253

58. Suvas S, Azkur AK, Rouse BT (2006) Qa-1b and CD94-NKG2a interaction regulate cytolytic activity of herpes simplex virus-specific memory CD8+ T cells in the latently infected trigeminal ganglia. J Immunol 176:1703-1711

59. Vance RE, Jamieson AM, Cado D, Raulet DH (2002) Implications of CD94 deficiency and monoallelic NKG2A expression for natural killer cell development and repertoire formation. Proc Natl Acad Sci USA 99:868-873

60. Wang J, Guan E, Roderiquez G, Calvert V, Alvarez R, Norcross MA (2001) Role of tyrosine phosphorylation in ligand-independent sequestration of CXCR4 in human primary monocytes-macrophages. J Biol Chem 276:49236-49243

61. Yasuda A, Kimura H, Hayakawa M, Ohshiro M, Kato Y, Matsuura O, Suzuki C, Morishima T (2003) Evaluation of cytomegalovirus infections transmitted via breast milk in preterm infants with a real-time polymerase chain reaction assay. Pediatrics 111:13331336 